(2) Open Access Full Text Article

\title{
Impact of combined pulmonary fibrosis and emphysema on surgical complications and long- term survival in patients undergoing surgery for non-small-cell lung cancer
}

\author{
This article was published in the following Dove Press journal: \\ International Journal of COPD \\ 9 June 2016 \\ Number of times this article has been viewed
}

\section{Atsushi Hata ${ }^{1,2}$ \\ Yasuo Sekine' \\ Ohashi Kota' \\ Eitetsu Koh' \\ Ichiro Yoshino \\ 'Department of Thoracic Surgery, Tokyo Women's Medical University Yachiyo Medical Centre, Yachiyo, ${ }^{2}$ Department of General Thoracic Surgery, Graduate School of Medicine, Chiba University, Chiba City, Chiba, Japan}

Purpose: The outcome of radical surgery for lung cancer was investigated in patients with combined pulmonary fibrosis and emphysema (CPFE).

Methods: A retrospective chart review involved 250 patients with lung cancer who underwent pulmonary resection at Tokyo Women's Medical University Yachiyo Medical Center between 2008 and 2012. Based on the status of nontumor-bearing lung evaluated by preoperative computed tomography (CT), the patients were divided into normal, emphysema, interstitial pneumonia (IP), and CPFE groups, and their clinical characteristics and surgical outcome were analyzed.

Results: The normal, emphysema, IP, and CPFE groups comprised 124 (49.6\%), 108 (43.2\%), seven $(2.8 \%)$, and eleven $(4.4 \%)$ patients, respectively. The 5 -year survival rate of the CPFE group $(18.7 \%)$ was significantly lower than that of the normal $(77.5 \%)$ and emphysema groups (67.1\%) $(P<0.0001$ and $P=0.0027$, respectively) but equivalent to that of the IP group $(44.4 \%)$ $(P=0.2928)$. In a subset analysis of cancer stage, the 5 -year overall survival rate of the CPFE group in stage $\mathrm{I}(\mathrm{n}=8,21.4 \%)$ was also lower than that of the normal group and emphysema group in stage $\mathrm{I}(\mathrm{n}=91,84.9 \%$ and $\mathrm{n}=70,81.1 \% ; P<0.0001$ and $P<0.0001$, respectively). During entire observation period, the CPFE group was more likely to die of respiratory failure $(27.2 \%)$ compared with the normal and emphysema groups $(P<0.0001)$. Multivariate analysis of prognostic factors using Cox proportional hazard model identified CPFE as an independent risk factor $(P=0.009)$.

Conclusion: CPFE patients have a poorer prognosis than those with emphysema alone or with normal lung on CT finding. The intensive evaluation of preoperative CT images is important, and radical surgery for lung cancer should be decided carefully when patients concomitantly harbor CPFE, because of unfavorable prognosis.

Keywords: combined pulmonary fibrosis and emphysema, lung cancer, surgical treatment, long-term outcomes

\section{Introduction}

Combined pulmonary fibrosis and emphysema (CPFE) is a clinical syndrome defined by upper lobe emphysema and lower lobe pulmonary fibrosis on computed tomography (CT). ${ }^{1,2}$

A previous report found that $8.9 \%$ of lung cancer patients had CPFE, and these patients had a poorer prognosis than those with emphysema alone. ${ }^{3}$ However, the impact of CPFE on the outcomes of lung cancer surgery has not been extensively investigated. ${ }^{4}$
Department of Thoracic Surgery, Tokyo Women's Medical University Yachiyo Medical Center, 477-96 Owadashinden, Yachiyo, Chiba 276-8524, Japan

Tel +8I 474506000

Fax +8I 474587047

Email sekine.yasuo@twmu.ac.jp 
The purpose of this study was to investigate the incidence of postoperative morbidity and mortality in patients with CPFE and lung cancer who underwent lung cancer surgery and to clarify the impact of the preoperative existence of CPFE on long-term survival after pulmonary resection for lung cancer.

\section{Patients and methods Patients}

This study was approved by the Institutional Review Board of Tokyo Women's Medical University, and informed consent was waived as the study was retrospective. The study population consisted of 250 consecutive patients with lung cancer who underwent pulmonary resection between April 2008 and January 2012 at Tokyo Women's Medical University Yachiyo Medical Center. Clinical data were collected from our institutional cancer registry database and from outpatient follow-up visits. The records contained preoperative patient characteristics, disease status, operative procedures, postoperative complications, pathological diagnosis, and follow-up data.

Based on the preoperative chest conventional CT or highresolution $\mathrm{CT}$, patients were divided into the following four groups: CPFE, emphysema, interstitial pneumonia (IP), and normal. CPFE was defined by the following CT findings: the combination of bilateral positive findings of a low attenuation area, which indicated 2 points or higher by the Goddard classification score ${ }^{5}$ in the upper field, and basal pulmonary fibrosis. ${ }^{1}$ The emphysema group was defined by diffuse bilateral positive findings of low attenuation area without an interstitial shadow on CT. The IP group was defined by the interstitial shadow without emphysema. The interstitial shadow was defined as fibrosis, subpleural curvilinear traction, bronchiolectasis, ground-glass opacities, and consolidation on CT findings. ${ }^{6}$ The remaining patients were categorized as the normal group. Of the 250 patients, eleven (4.4\%) were categorized as the CPFE group, 108 (43.2\%) as the emphysema group, and seven (2.8\%) as the IP group. The remaining 124 patients $(49.6 \%)$ were categorized as the normal group.

Preoperative evaluation for all patients included a detailed medical history, physical examination, blood and urine examinations, and a 12-lead electrocardiogram. Use of incentive nebulizers using distilled water with or without bronchodilator was routinely encouraged for enhancing lung expansion and airway clearance for $\sim 1$ week after surgery. Neoadjuvant or adjuvant therapy, consisting of platinum agent-based chemotherapy and radiation, was prescribed mainly for the patients who had locally advanced disease or multiple nodal involvement or who underwent incomplete resection. The postoperative morbidities were considered as those occurring within 30 days from the operation or during a longer period if the patient was still in the hospital. These included bacterial pneumonia (confirmed by infiltrative shadows on chest radiograph, positive sputum culture, body temperature $\geq 37.5^{\circ} \mathrm{C}$, and white blood cell count $>10,000 / \mu \mathrm{L}$ ), acute lung injury (aggravation of dyspnea on exertion, deterioration of respiratory function as indicated by arterial blood gas analysis, and diffuse interstitial abnormalities compatible with acute IP or exacerbation of IP in the CPFE group on chest radiograph and $\mathrm{CT}$ ), mechanical ventilation for $>3$ days, bronchial stump dehiscence, empyema and bronchial fistula (positive bacterial infection of a pleural effusion), tracheostomy, and postoperative home oxygen therapy for patients with partial pressure of oxygen $\left(\mathrm{PaO}_{2}\right)<55 \mathrm{mmHg}$ at rest or $<60 \mathrm{mmHg}$ on exercise at the time of hospital discharge. ${ }^{7}$

After discharge from the hospital, patients visited our outpatient clinic regularly every 1-6 months, unless the tumor recurred or the patient had any health problems. The overall survival was analyzed for each group of patients.

\section{Statistical analysis}

Data were analyzed using JMP11 software (SAS Institute Inc., Cary, NC, USA). To compare differences between the CPFE group and the other three groups, the Tukey-Kramer test was used to analyze continuous variables, and the Pearson's chi-square test was used for categorical variables. Survival curves were estimated using the Kaplan-Meier method, and differences in survival times between the CPFE group and the other three groups were calculated by the log-rank test. The Cox proportional hazards regression analysis was used to estimate the hazard ratio and the $95 \%$ confidence interval of each factor. Univariate Cox regression analysis model was used to identify significant factors. Multivariate Cox regression analysis model, with significant factor which had $P<0.05$ in univariate analysis, was used to identify prognostic factors.

\section{Results \\ Preoperative patient characteristics}

The preoperative patient characteristics are summarized in Table 1. Males were more predominant in the CPFE and emphysema groups than in the normal group, and the smoking index was higher in the CPFE and emphysema groups than in the normal group $(P<0.05)$.

Although the percentage of forced vital capacity $(\% \mathrm{FVC})$ and forced expiratory volume in 1 second $\left(\mathrm{FEV}_{1.0}\right) / \mathrm{FVC}$ in 
Table I Preoperative characteristics of lung cancer patients

\begin{tabular}{|c|c|c|c|c|c|}
\hline Characteristics & CPFE group $(n=I I)$ & Emphysema group $(n=108)$ & IP group $(n=7)$ & Normal group $(n=\mid 24)$ & $P$-value \\
\hline $\operatorname{Sex}(M / F)$ & II $(100 \%) / 0$ & $96(88.9 \%) / 12$ & $5(7 \mid .4 \%) / 2$ & $62(50 \%) / 62$ & $<0.0001$ \\
\hline Age (year) & $72.4 \pm 10.3$ & $70.8 \pm 7.1$ & $71.7 \pm 6.1$ & $69.8 \pm 8.2$ & ns \\
\hline BMI $\left(\mathrm{kg} / \mathrm{m}^{2}\right)$ & $23.1 \pm 3.8$ & $22.1 \pm 3.1$ & $20.1 \pm 2.3$ & $22.4 \pm 3.7$ & ns \\
\hline Smoking index (pack-year) & $46.8 \pm 31.7^{\mathrm{a}}$ & $57.5 \pm 31.3^{\mathrm{a}}$ & $37.9 \pm 36.6$ & $20.4 \pm 30.1$ & \\
\hline \multicolumn{6}{|l|}{ Pulmonary function tests } \\
\hline FVC & $2.90 \pm 0.69$ & $3.30 \pm 0.67^{\mathrm{a}}$ & $2.65 \pm 0.73$ & $2.90 \pm 0.71$ & \\
\hline$\% F V C$ & $93.7 \pm 18.4$ & $103.8 \pm 16.1$ & $91.5 \pm 20.5$ & $105.5 \pm 19.7$ & ns \\
\hline $\mathrm{FEV}_{1.0}$ & $2.05 \pm 0.5 \mathrm{I}$ & $3.58 \pm 10.67$ & $2.04 \pm 0.40$ & $2.15 \pm 0.54$ & ns \\
\hline$\% \mathrm{FEV}_{1.0}$ & $87.8 \pm 22.7^{\mathrm{a}}$ & $92.1 \pm 22.1^{\mathrm{a}}$ & $95.1 \pm 18.7$ & $109.9 \pm 22.2$ & \\
\hline $\mathrm{FEV}_{1.0} / \mathrm{FVC}$ & $71.2 \pm 9.8^{b}$ & $65.5 \pm I I .0^{\mathrm{a}, \mathrm{b}}$ & $86.8 \pm 30.1^{a, c}$ & $74.5 \pm 8.8^{\mathrm{b}, \mathrm{c}}$ & \\
\hline$\% \mathrm{DL}_{\mathrm{co}}$ & $71.3 \pm 20.8^{a}$ & $84.3 \pm 24.0^{\mathrm{a}}$ & $99.9 \pm 39.6$ & $108.2 \pm 27.0^{c}$ & \\
\hline$\% \mathrm{DL}_{\mathrm{CO}} / \mathrm{V}_{\mathrm{A}}$ & $69.2 \pm 19.7^{a}$ & $70.5 \pm 20.8^{\mathrm{a}, \mathrm{b}}$ & $88.8 \pm 22.4^{c}$ & $94.4 \pm 18.2^{c}$ & \\
\hline $\mathrm{PaO}_{2}$ & $92.8 \pm 23.7$ & $83.1 \pm 12.6$ & $86.3 \pm 9.9$ & $87.9 \pm 13.3$ & ns \\
\hline $\mathrm{PaCO}_{2}$ & $38.1 \pm 5.1$ & $39.1 \pm 3.9$ & $40.9 \pm 3.8$ & $39.0 \pm 3.1$ & ns \\
\hline
\end{tabular}

Notes: Data are presented as mean \pm SD. aP $<0.05$ for Tukey-Kramer test with data from normal group. ${ }^{b P}<0.05$ for Tukey-Kramer test with data from IP group. ${ }^{c P<0.05}$ for Tukey-Kramer test with data from emphysema group.

Abbreviations: CPFE, combined pulmonary fibrosis and emphysema; IP, interstitial pneumonia; M, male; F, female; BMI, body mass index; \%FVC, percentage of forced vital capacity; $\mathrm{FEV}_{1.0}$, forced expiratory volume in I second; \% $\mathrm{DL}_{\mathrm{co}}$, percentage of diffusion capacity of the lung for carbon monoxide; $\mathrm{V}_{\mathrm{A}}$, alveolar volume; $\mathrm{PaO}_{2}$, partial pressure of arterial oxygen; $\mathrm{PaCO}_{2}$, partial pressure of arterial carbon dioxide; SD, standard deviation; ns, not significant.

the CPFE group was similar to that in the normal groups, $\% \mathrm{FEV}_{1.0}$ and percentage of diffusion capacity of the lung for carbon monoxide $\left(\% \mathrm{DL}_{\mathrm{CO}}\right)$ in the CPFE group were significantly lower than that in the normal groups.

\section{Perioperative characteristics}

Perioperative characteristics are summarized in Table 2. Squamous cell carcinoma was predominant in the CPFE group, whereas adenocarcinoma was predominant in the other groups $(P<0.001)$. The type of operative procedure, pathological tumor status, pathological nodal status, and pathological staging were not different among the four groups.

\section{Postoperative morbidity and mortality}

Postoperative pulmonary complications within 30 days and the 30-day and 90-day mortality are summarized in Table 3. Pulmonary complications occurred in 15 of 250 patients (6\%)

Table 2 Perioperative characteristics of lung cancer patients

\begin{tabular}{|c|c|c|c|c|c|}
\hline Characteristics & $\begin{array}{l}\text { CPFE group } \\
(n=I I)\end{array}$ & $\begin{array}{l}\text { Emphysema } \\
\text { group }(n=108)\end{array}$ & $\begin{array}{l}\text { IP group } \\
(n=7)\end{array}$ & $\begin{array}{l}\text { Normal } \\
\text { group }(n=124)\end{array}$ & $P$-value \\
\hline \multicolumn{5}{|l|}{ Types of procedure } & \multirow[t]{4}{*}{0.959} \\
\hline Pneumonectomy & $0(0 \%)$ & $4(3.7 \%)$ & $0(0 \%)$ & $4(3.2 \%)$ & \\
\hline Lobectomy & $8(72.3 \%)$ & 87 (80.5\%) & $5(71.4 \%)$ & $98(79.0 \%)$ & \\
\hline $\begin{array}{l}\text { Segmentectomy/ } \\
\text { partial resection }\end{array}$ & $3(27.2 \%)$ & 17 (I5.7\%) & $2(28.5 \%)$ & $22(I 7.7 \%)$ & \\
\hline \multicolumn{6}{|l|}{ (maximal diameter) } \\
\hline \multicolumn{6}{|l|}{ Histologic diagnosis } \\
\hline $\mathrm{Ad} / \mathrm{Sq} / \mathrm{Oth}$ & $4 / 7 / 0$ & $51 / 45 / 12$ & $4 / 2 / 1$ & & \multirow[t]{2}{*}{$<0.001$} \\
\hline$\%$ & $36.4 / 63.6 / 0$ & $47.2 / 41.6 / 11.1$ & $57.1 / 28.5 / 14.2$ & $82.2 / 10.4 / 7.2$ & \\
\hline \multicolumn{6}{|l|}{ Pathological T status } \\
\hline $\mathrm{TI} / 2 / 3 / 4$ & $5 / 5 / 0 / 1$ & $49 / 48 / 10 / 1$ & $3 / 3 / 0 / 1$ & $72 / 37 / 8 / 7$ & \multirow[t]{2}{*}{0.138} \\
\hline$\%$ & 45.4./45.4/0/9.0 & $45.3 / 44.4 / 9.2 / 0.9$ & $42.8 / 42.8 / 0 / 14.2$ & $58.0 / 29.8 / 6.4 / 5.6$ & \\
\hline \multicolumn{6}{|c|}{ Pathological nodal status } \\
\hline $\mathrm{N} 0 / \mathrm{I} / 2 / 3$ & $8 / 3 / 0 / 0$ & $87 / 8 / 13 / 0$ & $5 / 1 / 1 / 0$ & $101 / 12 / 10 / 1$ & \multirow[t]{2}{*}{0.569} \\
\hline$\%$ & $72.7 / 27.7 / 0 / 0$ & $80.5 / 7.4 / 12.0 / 0$ & $71.4 / 14.2 / 14.2 / 0$ & $81.4 / 9.6 / 8.0 / 0.8$ & \\
\hline \multicolumn{6}{|l|}{ Pathological staging } \\
\hline I/II/III/IV & $8 / 2 / 1 / 0$ & $70 / 23 / 12 / 3$ & $4 / 1 / 2 / 0$ & $91 / 13 / 17 / 3$ & \multirow[t]{2}{*}{0.589} \\
\hline$\%$ & $72.7 / 18.1 / 9.0 / 0$ & $64.8 / 21.3 / 11.1 / 2.7$ & $57.1 / 14.2 / 28.5 / 0$ & $73.3 / 10.4 / 13.7 / 2.4$ & \\
\hline
\end{tabular}

Note: Data presented as mean \pm SD.

Abbreviations: CPFE, combined pulmonary fibrosis and emphysema; ns, not significant; IP, interstitial pneumonia; Ad, adenocarcinoma; Sq, squamous cell carcinoma; Oth, other histology; SD, standard deviation. 
Table 3 Postoperative pulmonary complications and mortality

\begin{tabular}{|c|c|c|c|c|c|}
\hline & CPFE group $(n=I I)$ & Emphysema group $(n=108)$ & IP group $(n=7)$ & Normal group $(n=124)$ & $P$-value \\
\hline Pneumonia & I (9.0\%) & $2(1.8 \%)$ & I (I4.2\%) & $0(0 \%)$ & 0.004 \\
\hline $\mathrm{ALI}$ & $0(0 \%)$ & $4(3.7 \%)$ & I (I4.2\%) & $2(1.6 \%)$ & 0.197 \\
\hline Prolonged mech vent & I (9.0\%) & $2(1.8 \%)$ & I (14.2\%) & $0(0 \%)$ & 0.004 \\
\hline HOT & I (9.0\%) & I (0.9\%) & $0(0 \%)$ & $0(0 \%)$ & 0.014 \\
\hline 30-day mortality & $0(0 \%)$ & $0(0 \%)$ & $0(0 \%)$ & $0(0 \%)$ & 1.000 \\
\hline 90-day mortality & I (9.0\%) & $3(2.7 \%)$ & $0(0 \%)$ & $0(0 \%)$ & 0.064 \\
\hline \multicolumn{6}{|l|}{ Causes of death } \\
\hline Primary cancer & $4(36.4 \%)$ & $16(14.8 \%)$ & I (I4.2\%) & $12(9.6 \%)$ & 0.08 \\
\hline Respiratory failure & $3(27.2 \%)$ & $2(0.9 \%)$ & $2(28.5 \%)$ & $\mathrm{I}(0.8 \%)$ & $<0.0001$ \\
\hline Others & $0(0 \%)$ & $6(5.5 \%)$ & $0(0 \%)$ & $2(1.6 \%)$ & 0.315 \\
\hline
\end{tabular}

Abbreviations: CPFE, combined pulmonary fibrosis and emphysema; IP, interstitial pneumonia; ALI, acute lung injury; mech vent, mechanical ventilation; HOT, home oxygen therapy.

overall and in two of eleven patients (18.2\%) in the CPFE group. There is significant difference among the four groups in postoperative bacterial pneumonia. CPFE patients and IP patients had high risk of postoperative pneumonia $(9.0 \%$ and $14.2 \%$, respectively). The 30 -day mortality was $0 \%$, and the 90-day mortality was $9.0 \%$ in the CPFE group. The 90-day mortality in the CPFE group was higher than other groups, but there is no significant difference among the four groups.

\section{Cause of death}

The causes of death in all groups are summarized in Table 3. The causes of death were divided into primary cancer, respiratory failure, and others. Death due to respiratory failure was associated with bacterial pneumonia or acute exacerbation (AE) of IP. Three CPFE patients died of respiratory failure, which was significantly different from the other three groups $(P=0.0001)$. The frequency of respiratory failure death in CPFE was also higher than that in the emphysema group $(P<0.0001)$ (Table 4). Two of the patients in the CPFE group experienced bacterial pneumonia or AE two or more times prior to their death. The time to $\mathrm{AE}$ ranged from 3 days to 1.5 years after surgery. There were no significant differences in the proportions of patients who died of their primary cancer or other causes among the four groups of patients $(P=0.080$ and $P=0.315$, respectively).

Table 4 Comparison of cause of death between CPFE and emphysema groups

\begin{tabular}{llll}
\hline & $\begin{array}{l}\text { CPFE } \\
\text { group (n=II) }\end{array}$ & $\begin{array}{l}\text { Emphysema } \\
\text { group (n=108) }\end{array}$ & P-value \\
\hline Cause of death & & & \\
Primary cancer & $4(36.4 \%)$ & $16(14.8 \%)$ & 0.068 \\
Respiratory failure & $3(27.3 \%)$ & $1(0.9 \%)$ & $<0.000 \mathrm{I}$ \\
Others & $0(0 \%)$ & $6(5.6 \%)$ & 0.422 \\
\hline
\end{tabular}

Abbreviation: CPFE, combined pulmonary fibrosis and emphysema.

\section{Survival analyses}

Figure 1 shows the overall survival after surgery. The mean follow-up period was 922 days in the CPFE group, 979 days in the emphysema group, 1,086 days in the IP group, and 1,117 days in the normal group. The cumulative survival at 3 years and 5 years was $50 \%$ and $18.7 \%$ in the CPFE group, $76.0 \%$ and $67.1 \%$ in the emphysema group, $44.4 \%$ and $44.4 \%$ in the IP group, and $85.9 \%$ and $77.5 \%$ in the normal group, respectively. Comparing with the CPFE group, there was significant difference in the normal group $(P<0.0001$, log-rank test) and the emphysema group $(P=0.0027$, logrank test). There was no significant difference between the CPFE group and the IP group $(P=0.2928$, log-rank test) (Figure 1).

The disease-specific survival at 5 years was $48.6 \%$ in the CPFE group, $81.7 \%$ in the emphysema group, $80 \%$ in the IP group, and $88.6 \%$ in the normal group, respectively (Figure 2). Comparing with the CPFE group, there was also

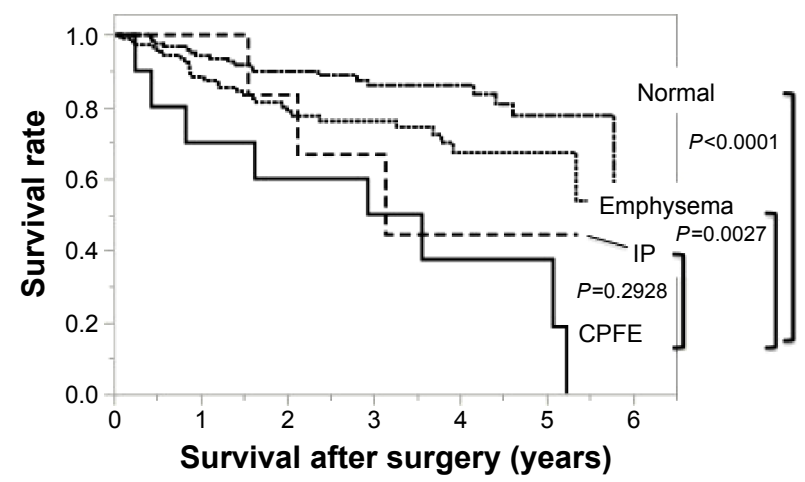

Figure I Overall survival in the four groups: Kaplan-Meier curves for OS after surgery. Notes: The cumulative survivals at 3 years and 5 years were $50.0 \%$ and $18.7 \%$ in the CPFE group, $76.0 \%$ and $67.1 \%$ in the emphysema group, $44.4 \%$ and $44.4 \%$ in the IP group, and $85.9 \%$ and $77.5 \%$ in the normal group, respectively. Comparing with the CPFE group, there was significant difference in the normal group $(P<0.000 \mathrm{I}$, log-rank test) and the emphysema group $(P=0.0027$, log-rank test).

Abbreviations: OS, overall survival; CPFE, combined pulmonary fibrosis and emphysema; IP, interstitial pneumonia. 


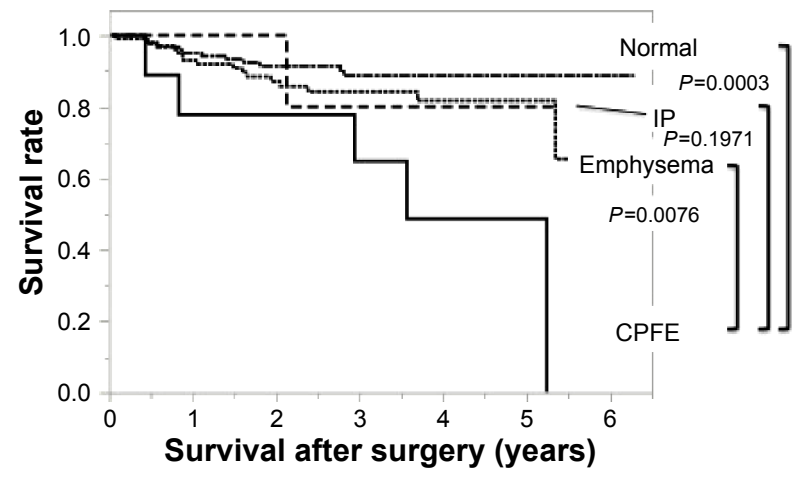

Figure 2 Disease-specific survival in the four groups: Kaplan-Meier curves for diseasespecific survival.

Notes: The disease-specific survival at 5 years was $48.6 \%$ in the CPFE group, $81.7 \%$ in the emphysema group, $80 \%$ in the IP group, and $88.6 \%$ in the normal group. Comparing with the CPFE group, there was significant difference in the normal group $(P=0.0003$, log-rank test $)$ and the emphysema group $(P=0.0076$, log-rank test). Abbreviations: CPFE, combined pulmonary fibrosis and emphysema; IP, interstitial pneumonia.

significant difference in the normal group $(P=0.0003$, logrank test) and the emphysema group $(P=0.0076$, log-rank test) but no difference in the IP group $(P=0.1971)$.

In patients with pathological stage I disease, the cumulative survival at 5 years was $21.4 \%$ in the CPFE group, $81.1 \%$ in the emphysema group, $50 \%$ in the IP group, and $84.9 \%$ in the normal group, respectively (Figure 3). Comparing with the CPFE group, there was significant difference in the normal group $(P<0.0001, \log$-rank test $)$ and the emphysema group $(P<0.0001, \log$-rank test) but no difference in the IP group $(P=0.2428, \log$-rank test).

We also attempted to clarify risk factors for long-term overall mortality (Tables 5 and 6 ). Univariate analysis

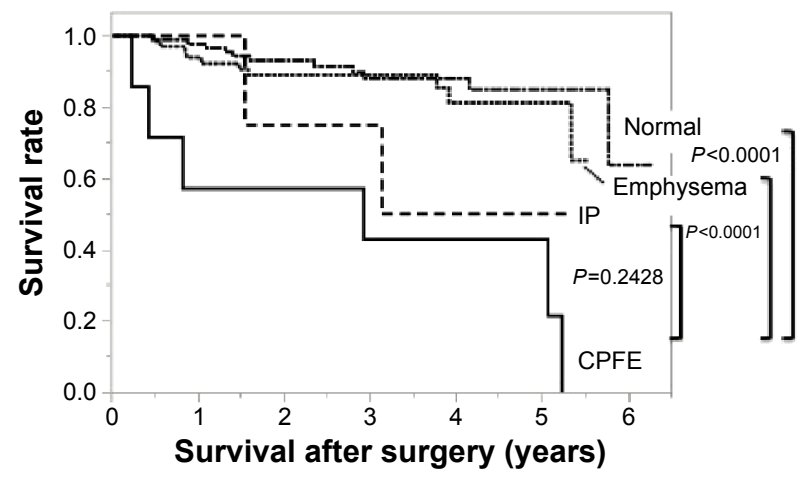

Figure 3 Overall survival in the four groups with pathological stage I disease: Kaplan-Meier curves for overall survival with pathological stage I disease.

Notes: The cumulative survival at 5 years was $21.4 \%$ in the CPFE group, $81.1 \%$ in the emphysema group, $50 \%$ in the IP group, and $84.9 \%$ in the normal group, respectively. Comparing with the CPFE group, there was significant difference in the normal group $(P<0.000 \mathrm{I}$, log-rank test) and the emphysema group $(P<0.0001$, log-rank test) but no difference in the IP group $(P=0.2428$, log-rank test).

Abbreviations: CPFE, combined pulmonary fibrosis and emphysema; IP, interstitial pneumonia. identified age, sex, smoking index, $\% \mathrm{FVC}, \% \mathrm{DL}_{\mathrm{CO}}, \% \mathrm{DL}_{\mathrm{CO}} /$ alveolar volume $\left(\mathrm{V}_{\mathrm{A}}\right)$, type of operative procedure, and pathological staging as significant factors (Table 5). Using these factors, we identified CPFE as an independent risk factor according to the Cox proportional hazard model $(P=0.009)$. Age, \%FVC, pathological stage III, and pathological stage IV were also independent risk factors $(P=0.007,0.006,0.012$, and 0.002 , respectively).

\section{Discussion}

The present study found that CPFE was an independent prognostic factor for patients with lung cancer undergoing surgery. The CPFE group had a poorer prognosis than any other groups in terms of overall survival. These results were consistent with a previous report. ${ }^{8}$ There was a significant difference among the four groups for respiratory failure as a cause of death but no significant difference in the rates of cancer death. However, the disease-specific survival of CPFE patients was also poorer than that of normal and emphysema groups. Kumagai et al pointed out that patients with CPFE had a high prevalence of cancer recurrence. ${ }^{8}$ They reported poor progression-free survival after operation and poor overall survival after recurrence in lung cancer patients with CPFE who underwent surgery. They suggested that CPFE patients have risk factors for lung cancer progression, including smoking, emphysema, and fibrosis. CPFE patients often cannot undergo an optimal chemotherapy after cancer recurrence because of a poor Eastern Cooperative Oncology Group Performance Status and AE after the administration of chemotherapy. Since our study found that four of eight CPFE patients with stage I disease experienced cancer recurrence, CPFE might have a high risk of cancer recurrence, as previously reported. ${ }^{8}$ Furthermore, five CPFE patients had chemotherapy or radiation because of cancer recurrence and two of five patients died due to respiratory failure after these therapies. Therefore, careful treatment planning should be undertaken for CPFE patients with any stage of lung cancer, because surgery and chemotherapy may lead to respiratory deficiency.

Assessment of respiratory function is useful for the prediction of prognosis of CPFE patients. ${ }^{9}$ The results of lung function testing in patients with CPFE differed markedly from that of patients with idiopathic pulmonary fibrosis (IPF) and that of patients with emphysema. ${ }^{1}$ The mean values of lung volumes of CPFE patients are near normal, but the $\mathrm{DL}_{\mathrm{CO}}$ values are markedly decreased. Hyperinflation and high compliance of the emphysematous areas of the lungs probably compensate for the volume loss due to 
Table 5 Univariate analysis of prognostic factors using Cox proportional hazard model

\begin{tabular}{|c|c|c|c|c|}
\hline Variable & Hazard ratio & $95 \% \mathrm{Cl}$ & $95 \% \mathrm{Cl}$ & $P$-value \\
\hline Age & 1.054804 & 1.000 & $\mathrm{I} .0007$ & 0.002 \\
\hline \multicolumn{5}{|l|}{ Sex } \\
\hline Female & Reference & & & \\
\hline Male & 2.830 & 1.452 & 6.203 & 0.0015 \\
\hline BMI & 0.965 & 0.893 & 1.038 & 0.350 \\
\hline Smoking index & 1.000 & 1.000 & 1.000 & 0.010 \\
\hline \multicolumn{5}{|l|}{ Pulmonary function data } \\
\hline$\% F V C$ & 0.979 & 0.969 & 0.990 & 0.0007 \\
\hline$\% \mathrm{FEV}_{1.0}$ & 0.993 & 0.982 & 1.004 & 0.263 \\
\hline $\mathrm{FEV}_{1.0} / \mathrm{FVC}$ & 1.007 & 0.984 & 1.029 & $0.5 \mathrm{II}$ \\
\hline$\% \mathrm{DL}_{\mathrm{cO}}$ & 0.982 & 0.969 & 0.994 & 0.004 \\
\hline$\% D L_{C O} / V_{A}$ & 0.983 & 0.968 & 0.997 & 0.023 \\
\hline \multicolumn{5}{|l|}{ Type of procedure } \\
\hline Segmentectomy/partial resection & Reference & & & \\
\hline Lobectomy & $\mathrm{I} .44 \mathrm{I}$ & 0.716 & 3.309 & 0.322 \\
\hline Pneumonectomy & 4.200 & 1.265 & 12.634 & 0.021 \\
\hline \multicolumn{5}{|l|}{ Pathological stage } \\
\hline 1 & Reference & & & \\
\hline$\|$ & 2.498 & 1.209 & 4.878 & 0.014 \\
\hline III & 3.829 & 1.974 & 7.167 & 0.0002 \\
\hline IV & 2.087 & 0.336 & 6.979 & 0.365 \\
\hline \multicolumn{5}{|l|}{ Group } \\
\hline Normal & Reference & & & \\
\hline CPFE & 6.147 & 2.515 & 13.730 & 0.0002 \\
\hline Emphysema & 2.021 & 1.126 & 3.720 & 0.018 \\
\hline IP & 2.843 & 0.665 & 8.425 & 0.139 \\
\hline
\end{tabular}

Abbreviations: $\mathrm{Cl}$, confidence interval; $\mathrm{BMI}$, body mass index; \% FVC, percentage of forced vital capacity; $\mathrm{FEV}_{10}$, forced expiratory volume in I second; \%DL $\mathrm{L}_{\mathrm{co}}$, percentage of diffusion capacity of the lung for carbon monoxide; $\mathrm{V}_{\mathrm{A}}$, alveolar volume; CPFE, combined pulmonary fibrosis and emphysema; IP, interstitial pneumonia.

Table 6 Multivariate analysis of prognostic factors using Cox proportional hazard model

\begin{tabular}{|c|c|c|c|c|}
\hline Variable & Hazard ratio & $95 \% \mathrm{Cl}$ & $95 \% \mathrm{Cl}$ & $P$-value \\
\hline Age & 1.087 & 1.022 & 1.16 & 0.007 \\
\hline \multicolumn{5}{|l|}{ Sex } \\
\hline Female & Reference & & & \\
\hline Male & 2.495 & 0.720 & 12.26 & 0.160 \\
\hline Smoking index & 1.000 & 0.999 & 1.000 & 0.305 \\
\hline \multicolumn{5}{|l|}{ Pulmonary function data } \\
\hline$\% F V C$ & 0.968 & 0.946 & 0.99 & 0.006 \\
\hline$\% \mathrm{DL}_{\mathrm{co}}$ & 0.989 & 0.966 & 1.012 & 0.377 \\
\hline$\% D L_{C O} / V_{A}$ & 0.995 & 0.966 & 1.026 & 0.791 \\
\hline \multicolumn{5}{|l|}{ Type of procedure } \\
\hline Segmentectomy/partial resection & Reference & & & \\
\hline Lobectomy & 2.731 & 0.857 & 10.24 & 0.091 \\
\hline Pneumonectomy & 3.656 & 0.612 & 21.89 & 0.152 \\
\hline \multicolumn{5}{|l|}{ Pathological stage } \\
\hline I & Reference & & & \\
\hline II & 2.288 & 0.766 & 6.302 & 0.132 \\
\hline III & 3.370 & 1.308 & 8.510 & 0.012 \\
\hline IV & 36.35 & 4.241 & 234.6 & 0.002 \\
\hline \multicolumn{5}{|l|}{ Group } \\
\hline Normal & Reference & & & \\
\hline CPFE & 8.004 & 1.712 & 34.62 & 0.009 \\
\hline Emphysema & 1.562 & 0.635 & 4.146 & 0.337 \\
\hline IP & 5.996 & 1.079 & 27.79 & 0.041 \\
\hline
\end{tabular}

Abbreviations: $\mathrm{Cl}$, confidence interval; \% FVC, percentage of forced vital capacity; \% $\mathrm{DL}_{\mathrm{co}}$, percentage of diffusion capacity of the lung for carbon monoxide; $\mathrm{V}_{\mathrm{A}}$, alveolar volume; CPFE, combined pulmonary fibrosis and emphysema; IP, interstitial pneumonia. 
fibrosis of the lower lobes, while pulmonary emphysema and fibrosis may have synergistic effects on $\mathrm{DL}_{\mathrm{CO}}$ and exercise hypoxemia.

CPFE might be underrecognized in patients with subnormal or normal spirometry if $\mathrm{DL}_{\mathrm{CO}}$ and/or exercise blood gases are not measured. ${ }^{9}$ Compared with the normal group, CPFE patients had low $\% \mathrm{FEV}_{1.0}$ and $\% \mathrm{DL}_{\mathrm{CO}}$ and similar $\% \mathrm{FVC}$ and $\mathrm{FEV}_{1.0} / \mathrm{FVC}$. In addition, patients with CPFE tended to die of respiratory failure more often than the normal and emphysema patients (Tables 4 and 5).

$\mathrm{DL}_{\mathrm{CO}}$ measures the ability of gas to diffuse across the alveolar-capillary membrane and assesses the surface area and pulmonary capillary blood volume available for gas exchange. ${ }^{10}$ The preoperative $\mathrm{DL}_{\mathrm{CO}}$ expressed as percentage of predicted has a higher correlation with postoperative deaths than the $\mathrm{FEV}_{1.0}$ expressed as percentage of predicted. ${ }^{11}$ Our study showed $\% \mathrm{DL}_{\mathrm{CO}}$ was a significant factor for overall survival in the univariate analysis. Some studies found that a reduced predicted postoperative $\mathrm{DL}_{\mathrm{CO}}$ was strongly associated with the risk of pulmonary morbidity, mortality, and poor long-term survival following lung resection. ${ }^{12,13}$

Similar to previous reports, our study showed no significant difference in long-term survival between the CPFE and IP groups. ${ }^{3,8,14,15}$ This suggests that IP has a higher impact on the outcome of lung cancer patients than emphysema. However, Schmidt et al clarified the importance of evaluation for emphysema in CPFE patients. ${ }^{9}$ They reported the efficiency of the composite physiological index that was calculated from the following formula: $91-(0.65 \times$ \%predicted $\left.\mathrm{DL}_{\mathrm{CO}}\right)-(0.53 \times \%$ predicted FVC $)+(0.34 \times$ \%predicted $\mathrm{FEV}_{1.0}$ ) in IPF. This index was a powerful predictor of mortality in IPF patients. They showed that change in $\mathrm{FEV}_{1.0}$ was the best predictor of mortality in CPFE. Therefore, evaluation of the air obstruction status in CPFE patients may still be important.

Our study showed that CPFE patients with lung cancer also had a high risk of death due to respiratory failure caused by bacterial infection or AE. In this study, one patient with CPFE died due to AE of IP, and two died due to bacterial pneumonia. These types of death might be associated with impaired immunity, which is involved in the pathogenesis of CPFE. Aging lung and cellular senescence have been reported to be involved in the pathogenesis of IPF and emphysema. ${ }^{16}$ Exposure to a variety of toxic substances such as those in smoking can contribute to the acceleration of pulmonary senescence. Premature aging can impair lung function by inducing systemic and/or local changes in the immune system, impairing the complex pulmonary mechanisms of defense against infection and stimulating a local and/or systemic inflammatory condition. This phenomenon and surgical stress may lead to deterioration of the pulmonary immune responses.

This study has several limitations. First, this was a retrospective and uncontrolled study performed at a single institution. The results may have been subject to selection and treatment bias. The indications for therapy were not uniform for all patients, thereby limiting the evaluation of the effects of treatment. Second, this study included a relatively small number of patients with CPFE. Therefore, there may be several confounding variables. Third, high-resolution chest CT was not always utilized, and the pathological evaluation of fibrotic lesions was not always performed.

\section{Conclusion}

In conclusion, lung cancer patients with CPFE who undergo surgery have a worse prognosis than surgical lung cancer patients with emphysema alone or surgical lung cancer patients with normal lung because they tend to die of respiratory failure. The intensive evaluation of preoperative CT images and assessment of $\mathrm{DL}_{\mathrm{CO}}$ are important for planning cancer treatment for CPFE patients, and great care should be taken when deciding on specific treatments.

\section{Acknowledgments}

The abstract of this paper was presented at the 23rd European Conference on General Thoracic Surgery Conference as a poster presentation with interim findings. The poster's abstract was published in "Poster Abstracts" in Interactive CardioVasc Thoracic Surgery: Hyperlink (http://icvts. oxfordjournals.org/content/21/suppl 1/S27.4.full). The actual paper, however, has never been published.

\section{Disclosure}

YS received a Grant-in-Aid for Scientific Research (26462139) from the Ministry of Education, Culture, Sports, Science and Technology of Japan in support of this work. The authors report no other conflicts of interest in this work.

\section{References}

1. Cottin V, Nunes H, Brillet PY, et al. Combined pulmonary fibrosis and emphysema: a distinct underrecognised entity. Eur Respir J. 2005; 26(4):586-593.

2. Bouros D. Combined pulmonary fibrosis and emphysema syndrome Pneumon. 2009;22(2):128-130.

3. Usui K, Tanai C, Tanaka Y, Noda H, Ishihara T. The prevalence of pulmonary fibrosis combined with emphysema in patients with lung cancer. Respirology. 2011;16(2):326-331. 
4. Sekine Y, Sakairi Y, Yoshino M, et al. The impact of combined pulmonary fibrosis and chronic obstructive pulmonary disease on long-term survival after lung cancer surgery. Thorac Cardiovasc Surg. 2014; 62(4):332-337.

5. Goddard PR, Nicholson EM, Laszlo G, Watt I. Computed tomography in pulmonary emphysema. Clin Radiol. 1982;33(4):379-387.

6. Suzuki H, Sekine Y, Yoshida S, et al. Risk of acute exacerbation of interstitial pneumonia after pulmonary resection for lung cancer in patients with idiopathic pulmonary fibrosis based on preoperative high-resolution computed tomography. Surg Today. 2011;41(7):914-921.

7. Sekine Y, Chiyo M, Iwata T, et al. Impact of interstitial lung disease on surgical morbidity and mortality for lung cancer: analyses of short and long-term outcomes. J Thorac Cardiovasc Surg. 2003; 126(4):1141-1146.

8. Kumagai S, Marumo S, Yamanashi K, et al. Prognostic significance of combined pulmonary fibrosis and emphysema in patients with resected non-small-cell lung cancer: a retrospective cohort study. Eur J Cardiothorac Surg. 2014;46(6):113-119.

9. Schmidt SL, Nambiar AM, Tayob N, et al. Pulmonary function measures predict mortality differently in IPF versus combined pulmonary fibrosis and emphysema. Eur Respir J. 2011;38(1):176-183.
10. Liptay MJ, Basu S, Hoaglin MC, et al. Diffusion lung capacity for carbon monoxide (DLCO) is an independent prognostic factor for long-term survival after curative lung resection for cancer. J Surg Oncol. 2009; 100(8):703-707.

11. Ferguson MK, Little L, Rizzo L, et al. Diffusing capacity predicts morbidity and mortality after pulmonary resection. J Thorac Cardiovasc Surg. 1988;96(6):894-900.

12. Ferguson MK, Reeder LB, Mick R. Optimizing selection of patients for major lung resection. J Thorac Cardiovasc Surg. 1995; 109(2):275-281.

13. Santini M, Fiorello A, Vicidomini G, Di Crescenzo VG, Laperuta P. Role of diffusing capacity in predicting complications after lung resection for cancer. Thorac Cardiovasc Surg. 2007;55(6):391-394.

14. Minegishi Y, Kokuho N, Miura Y, et al. Clinical features, anti-cancer treatments and outcomes of lung cancer patients with combined pulmonary fibrosis and emphysema. Lung Cancer. 2014;85(2):258-263.

15. Papiris SA, Triantafillidou C, Manali ED, et al. Combined pulmonary fibrosis and emphysema. Expert Rev Respir Med. 2013;7(1):19-31.

16. Chilosi M, Carloni A, Rossi A, Poletti V. Premature lung aging and cellular senescence in the pathogenesis of idiopathic pulmonary fibrosis and COPD/emphysema. Transl Res. 2013;162(3):156-173.

\section{Publish your work in this journal}

The International Journal of COPD is an international, peer-reviewed journal of therapeutics and pharmacology focusing on concise rapid reporting of clinical studies and reviews in COPD. Special focus is given to the pathophysiological processes underlying the disease, intervention programs, patient focused education, and self management protocols.

\section{Dovepress}

This journal is indexed on PubMed Central, MedLine and CAS. The manuscript management system is completely online and includes a very quick and fair peer-review system, which is all easy to use. Visit $\mathrm{http}: / / \mathrm{www}$.dovepress.com/testimonials.php to read real quotes from published authors. 